\title{
INTRODUCCIÓN AL ESTUDIO DE LOS
}

\section{ESPACIOS INTERNODALES Y SU APORTE A LA HISTORIA, NATURALEZA Y DINÁMICA DE LAS OCUPACIONES HUMANAS EN ZONAS ÁRIDAS}

\author{
José Berenguer R. ${ }^{1}$ y Gonzalo Pimentel G. ${ }^{2}$
}

Este número de Estudios Atacameños compila los resultados del simposio referido en el título de esta Introducción. Dicho simposio tuvo lugar el 8 de octubre de 2015 en la ciudad de Concepción, en el marco del XX Congreso Nacional de Arqueología Chilena, y fue organizado por la carrera de Antropología de la Universidad de Concepción en conjunto con la Sociedad Chilena de Arqueología. Se expusieron en la ocasión 16 ponencias, presentadas por más de 30 investigadores de Chile, Argentina y Estados Unidos, las que fueron comentadas por Axel Nielsen al cierre del encuentro.

Antes de recordar los principales enunciados que marcaron nuestra convocatoria a ese simposio, permítasenos hacer un poco de historia acerca del concepto de espacio internodal y ofrecer algunas ideas sobre cómo ha ido evolucionando hasta transformarse en un nuevo enfoque de la arqueología.

\section{* Breve historia del concepto}

Formas larvadas de las ideas de "nodos" y "espacios internodales" pueden encontrarse en Berenguer (1994: 30-31, 1995: 200) y en Nielsen (1997, 1998). Ambos atisbos del concepto obedecían a la necesidad que tenían los autores de encontrar una noción que posibilitara abordar el tráfico de caravanas -en un caso desde la arqueología de Santa Bárbara, Alto Loa, y en el otro desde la etnoarqueología de los llameros de Lípez-, destacando no tanto los bienes exógenos transportados como los agentes y prácticas que los hacían circular. En sus respectivas tesis de doctorado, Berenguer y Nielsen necesitaban argumentar que el registro arqueológico generado en esos espacios intermedios o intersticiales podía mostrar algo relevante (y en lo posible único) sobre la interacción interregional, que no era factible encontrar investigando los poblados de destino.

El concepto decanta finalmente entre el 8 y el 10 de diciembre de 2001, en un viaje en camioneta que Berenguer y Nielsen hacen al río Loa superior, gracias a un proyecto de Cooperación Internacional asociado a otro mayor sobre el Qhapaq Ñan en el Alto Loa. ${ }^{3}$ El objetivo del viaje es discutir en terreno si los sitios ubicados junto al tambillo de Incaguasi eran o no paraderos de caravanas, pero el recorrido por

1 Museo Chileno de Arte Precolombino, Santiago, CHILE. Email: jberenguer@museoprecolombino.cl

2 IAA-San Pedro de Atacama, Universidad Católica del Norte. Fundación Patrimonio Desierto de Atacama. CHILE. Email: gpimentel@desiertoatacama.com

3 Proyectos Fondecyt 7010327 y 1010327 , respectivamente. 
este valle, la localidad de Lasana y la cuenca del río Salado precipita el concepto de internodo, en parte por las extensas franjas desérticas que el vehículo atraviesa entre los poblados o nodos, mientras discuten sobre tráfico de caravanas. En parte precipita también por defectos (más que las virtudes) que encuentran en la noción de "espacios vacíos" formulada una década antes por Upham (1992) para la arqueología del sudoeste de los Estados Unidos.

En los años siguientes, el concepto es rápidamente aplicado por ambos en sus respectivas publicaciones sobre tráfico e interacción interregional (Berenguer 2002, 2004; Nielsen 2006). Su "estreno en sociedad", sin embargo, se produce en 2006, en el VIII Simposio "Arqueología de los 'Espacios Vacíos': Una Aproximación Internodal a las Relaciones Intersocietales”, en el XVII Congreso Nacional de Arqueología Chilena, en Valdivia (Berenguer y Pimentel 2010). El 13 de octubre de ese año, una masiva concurrencia abarrota una de las principales salas de eventos de la Universidad Austral de Chile para escuchar la introducción al simposio, las diez ponencias inscritas y los comentarios finales de Tom Dillehay y José Luis Martínez, todo en torno a un concepto que, por tratarse de un tema emergente, muy pocos habían oído antes: espacio internodal o internodo. Según nuestra definición, inspirada parcialmente en la de "espacios vacíos" de Upham (1992), estos espacios son áreas situadas entre los nodos más que en sus márgenes. La definición original de este último es bastante hábil en neutralizar la típica monserga de los críticos de las conceptualizaciones tipo centroperiferia, pero no nos convence de la validez de la noción de "espacios vacíos". A pesar de que incluimos esta expresión en el título del simposio, lo hacemos entre comillas, para señalar reticencia y en la convocatoria manifestamos derechamente preferir el de espacios internodales: "[Estos espacios] nunca son o están enteramente vacíos [...] suelen ser áreas de población escasa o dispersa, pero rara vez demográficamente vacantes, por lo que en vez de 'espacios vacíos' proponemos llamarlos "espacios internodales" (Berenguer y Pimentel 2010; véase también Berenguer 2002; Nielsen 2006).

Con el tiempo se han agregado razones más políticas. Históricamente, lenguajes de valoración como el de "espacios vacíos", al igual que términos como "despoblado", "tierras vacías", "nichos desocupados", "espacios estériles", "te- rritorios improductivos", etcétera, han sido instrumentales para "justificar la construcción de territorialidades que excluyen a las otras existentes, como ocurrió con la ocupación de los territorios indígenas por los Estados nacionales y como sigue ocurriendo actualmente con la apropiación de territorios por la gran minería (Svampa 2009; véase también Lightfoot y Martínez 1995).

Si bien los estudios internodales se originan en la investigación del tráfico y la interacción, la convocatoria de 2006 reconoce que un importante estímulo, al menos en el norte de Chile, ha venido de las investigaciones sobre la vialidad prehispánica, que han llevado a los arqueólogos lejos de las zonas nodales; de los avances tecnológicos en el acceso y manipulación digital de imágenes satelitales, que han permitido explorar en forma remota el territorio como nunca antes; de los estudios de impacto ambiental, que han proporcionado una gran cantidad de evidencia sobre sitios y rasgos usualmente no considerados (y muchas veces ni siquiera sospechados) por la arqueología nodal y tanto de la arqueología del paisaje como de la reinserción del espacio como un elemento clave en la teoría social.

\section{* De concepto a enfoque}

Una década después de ese primer simposio, el estudio de los espacios internodales ha dejado de ser un tema emergente, para convertirse en un tópico relativamente establecido en la disciplina, tanto en Chile como en Argentina, faltando ahora una proyección más internacional.

Como producto de lo anterior, en los últimos años se ha producido un cambio de enfoque de tipo no sustitutivo en el estudio arqueológico del tráfico. A una mirada centrada exclusivamente en los restos materiales presentes en los lugares de partida y de destino de la circulación interregional, ha venido a sumarse otra focalizada en los propios espacios por donde ocurre y discurre dicha circulación. En otras palabras: la clásica aproximación nodal al tráfico y la interacción interregional se han visto complementadas con la aproximación internodal, donde las zonas "entre los nodos" han dejado de ser simples espacios vacíos o lugares en blanco en el mapa, para ser visualizadas como teatros de operación de una renovada arqueología de la movilidad desarrollada en "espacios reales". 
Actualmente, la "arqueología internodal" contribuye a la investigación de los procesos sociales a través del estudio de las áreas entre nodos, es decir, aquellos lugares donde las actividades humanas y las interacciones tienden a agruparse (sitios o áreas densamente pobladas, dependiendo de la escala). Al centrarse en las huellas materiales generadas directamente por el movimiento de las personas, en lugar de evidencias secundarias como los artículos exógenos o no locales desechados en los nodos, este enfoque posee un gran potencial para abordar preguntas acerca de quiénes viajaron a través de las regiones y por qué razones. Junto con la evidencia nodal provista por contextos domésticos y funerarios recuperados en asentamientos y comunidades consumidoras, el registro arqueológico de los espacios internodales puede proporcionar una visión más completa de los sistemas sociales y sus cambios a lo largo del tiempo y a través del espacio (Nielsen et al. 2017).

En la arqueología del Norte Grande de Chile, la circulación - entendida como el desplazamiento de personas, ideas y cosas a través del espacio geográfico- ha sido abordada principalmente desde los asentamientos estables, permanentes o fijos que radican en las quebradas, valles y oasis del desierto chileno. En esa mirada a la movilidad local, regional e interregional, los productos exógenos al lugar se han considerado como las mejores pruebas de antiguos desplazamientos e interacciones con otros lugares o grupos, dando origen a interpretaciones en términos de circuitos de trashumancia (Lynch 1989), relaciones de intercambio (Browman 1980), operaciones de colonización (Núñez et al. 1975) o redes de tráfico de caravanas (Núñez 1976), que han conducido en algunos casos a la formulación de amplios modelos históricos y procesuales de movilidad e interacción que abarcan más de 10 mil años de desarrollo cultural (Núñez y Dillehay 1979).

Han sido muy pocos, sin embargo, los esfuerzos por estudiar la circulación en los terrenos mismos donde ella ocurría, es decir, en los propios espacios de circulación (Berenguer 2004; Berenguer et al. 2011; Núñez 1985; Pimentel 2009). Esta manera alternativa de abordar la circulación, denominada enfoque internodal (Berenguer 2004; Berenguer y Pimentel 2010; Nielsen 2006), coloca las vías en el centro de este tipo de estudio, imprimiendo mayor contenido empírico a conceptos como vínculos de intercambio, vectores de tráfico, franjas de interacción, complementariedad económica, relaciones interétnicas y tantas otras nociones usadas o ideadas en los Andes para entender, describir o sencillamente denominar las articulaciones que establecen los individuos a través de esos espacios internodales (Berenguer et al. 2011).

Existen por lo menos tres aspectos que es necesario tener en cuenta al abordar la circulación humana con este enfoque internodal: su diversidad tipológica, ciertas propiedades adquiridas por los espacios por donde ella discurre y la expresión material de tales movimientos.

Tipos de circulación: La circulación se ha estudiado en gran parte como si solo estuviese orientada a obtener recursos que no se encuentran en el lugar de origen. La importancia de la explotación directa de recursos lejanos o indirecta vía intercambios con otros grupos en la consecución de ese objetivo de la movilidad no puede disminuirse, pero es claro que la gente se movía a causa de una multiplicidad de otras razones, incluyendo visitas para establecer o cultivar vínculos sociales, peregrinaciones a lugares de culto, abastecimiento de grupos de tareas, exploración de nuevas rutas o nichos, asistencia a festividades de otras comunidades, incursiones hostiles en otros territorios, obtención de información de interés, acceso a servicios de ciertos especialistas, etcétera. De ahí que identificar esta diversidad tipológica sea un importante objetivo en cualquier investigación arqueológica de la circulación.

Territorios circulatorios: Con el correr del tiempo, toda movilidad humana va creando lo que se denomina "espacios circulatorios" (Tapia Ladino y Ovando Santana 2013), o sea, espacios que se construyen esencialmente circulando por ellos. Si estos espacios comienzan a ser apropiados por un grupo, comunidad o cualquier otra colectividad cuyos miembros pueden emplear un "nosotros" que los identifique, se habla entonces de la creación de un "territorio circulatorio" (Tarrius 2000). Puesto que lo usual es que estos espacios sean ocupados y atravesados por individuos de diversos orígenes, en la práctica casi siempre se producen traslapes o solapamientos de distintos "territorios circulatorios". Otra propiedad de estos espacios es que están conectados, como mínimo, con el nodo de origen del individuo o del grupo circulante, pero a veces también con al menos un nodo de destino 
en el otro extremo de una travesía. No obstante, mientras más compleja y extensa es la movilidad soportada por un espacio circulatorio, nodalidades simples o bipolares como las mencionadas recién "evolucionan" a nodalidades múltiples. La descripción e interpretación de estos territorios de circulación, sus respectivas afiliaciones culturales y sus cambios en el tiempo son también importantes objetivos en una arqueología de la circulación.

Materialidad de la circulación: Este concepto engloba las estructuras (construcciones), rasgos (p.e., vías), artefactos (objetos creados por humanos) y ecofactos (p.e. polen, carbón, madera, restos de animales) dejados por el trajín de individuos y grupos en sus recorridos a través de los espacios circulatorios. Es esta clase de evidencias materiales la que permite investigar arqueológicamente un espacio internodal en términos de una secuencia de los cambios en el tipo de circulación humana desarrollada en esos territorios. Dentro del ítem "estructuras" se espera encontrar estaciones de tráfico tales como paskanas, tambos y tambillos (Berenguer et al. 2005; Nielsen 2006; Núñez et al. 2003; Pimentel 2013), refugios de tarea (p.e., asociados a labores extractivas), refugios de circunstancia (Berenguer et al. 2011), entierros de circunstancia (Cases et al. 2008; Torres-Rouff et al. 2012). Dentro de la categoría "vías" la expectativa es hallar senderos peatonales, senderos troperos prehispánicos de llamas e históricos de equinos, caminos, huellas de carretas y sendas procesionales (Berenguer 2004; Berenguer et al. 2005; Pimentel 2013). Otros elementos que se espera encontrar asociados a las vías son "estructuras indicadoras", esto es, dispositivos que comunican o ponen de manifiesto un hecho, tales como mojones, sayhuas (Sanhueza 2012), geoglifos (Briones et al. 2005; Núñez 1976; Pimentel 2011), sitios de muros y cajas (Berenguer 2004), círculos de piedra (Bittman 1985), "sepulcros" u oquedades artificiales (Nielsen 1997; Pimentel 2009), apachetas, camachicosy alineamientos de piedras (Pimentel et al. 2017), montículos circulares con piedras de diferentes colores (Martel 2011). También está dentro de las posibilidades ubicar canteras, talleres de reducción de material lítico y yacimientos mineros (Blanco et al. 2010; Núñez et al. 2003; Pimentel et al. 2011). La expresión material de las circulaciones es la que permite contextualizarlas a lo largo del tiempo y a través del espacio geográfico.
En la convocatoria al presente simposio, propusimos concentrarnos en situaciones de zonas áridas, definiendo estas últimas como "aquéllas que tienen menos de $250 \mathrm{~mm}$ de precipitaciones al año" (Aronson 2008: 29). Estas zonas del globo cubren alrededor de $25.500 .000 \mathrm{~km} 2$, equivalentes al $20 \%$ de la superficie terrestre (Smith et al. 2005: 2). Las estadísticas de UNDA/UNSO muestran que en ellas viven aproximadamente unos 313 millones de habitantes (Smith y Hesse 2005), por lo tanto las densidades de población en estos territorios son generalmente muy bajas (Veth 2005). Una característica que es común a muchas de estas zonas es que presentan nodos de agregación de población separados por amplias áreas casi despobladas. La nodalidad de la vida social, esto es, la agrupación o aglomeración de actividades humanas en nodos geográficos, ha sido advertida por muchos autores (p.e., Soja 1989), pero muy pocos (notablemente Upham 1992) han prestado atención a aquellos extensos intersticios situados entre esos nodos (más que en sus bordes), donde la nodalidad disminuye hasta aproximarse o igualarse a cero (Berenguer et al. 2011).

El énfasis de la convocatoria de 2006 estuvo en explorar en forma interdisciplinaria la manera como estos espacios pueden informarnos acerca de las relaciones entre sociedades a escala local, regional e interregional (Berenguer y Pimentel 2010). En la convocatoria de 2015 se quiso mantener la diversidad de miradas disciplinarias del simposio de 2006, pero ampliando el foco de interés a las variadas formas en que el estudio de estos espacios internodales puede ayudarnos a comprender la historia, la naturaleza y la dinámica de las ocupaciones humanas.

Temas como asentamientos y subsistencia, explotación de recursos distantes, ritualidad y funebria, patrones de desarrollo de corto, mediano y largo plazo, vialidad, transporte y circulación de bienes, arte rupestre, producción de territorios, creación de enclaves, identidades sociales, afiliaciones culturales, historias de vida, fueron especialmente bienvenidos. Sin embargo, el simposio estuvo abierto también a tópicos no contemplados en esta lista, como asimismo a aportes provenientes de zonas no necesariamente áridas o semiáridas, siempre que trataran situaciones localizadas en espacios internodales o intersticiales. 
Diez de esas ponencias integran esta compilación. En el presente volumen se incluyen trabajos que provienen de investigaciones internodales producidas principalmente en el desierto de Atacama con seis artículos referidos a esta área, cubriéndose desde la localidad de Pica en la región de Tarapacá hasta la localidad de El Salvador en la región de Atacama (Berenguer y Salazar; Blanco et al.; Borie et al.; González et al.; Núñez y Briones; Pimentel et al.). La vertiente oriental de la cordillera de los Andes está incorporada con las investigaciones desarrolladas por los investigadores argentinos en la puna catamarqueña (Martel et al.) y en la Patagonia septentrional (Barberena et al.; Berón et al.). Un trabajo de integración macrorregional es el que nos brinda Gil Montero et al., en el cual se incluyen las provincias de Atacama, Lípez y Chichas de fines del siglo XVII.

En cuanto a la época prehispánica, los trabajos reúnen evidencias directas de la movilidad del Período Arcaico del norte de Chile (ca. $7000 \mathrm{AP}$ ) (Blanco et al.; Borie et al.; Pimentel et al.), del Holoceno Tardío de la Patagonia norte (Barberena et al.; Berón et al.), del Período Formativo (González et al; Martel et al.; Pimentel et al.), del Período Intermedio Tardío y Tardío (Berenguer y Salazar; Núñez y Briones; Pimentel et al.), del período Colonial (Berenguer y Salazar; Gil Montero et al.) y republicano (Berenguer y Salazar). Así, en su conjunto son representativos de los últimos 7 mil años de la circulación internodal preindustrial.

\section{* Los senderos de la memoria y la ontología andina. Miradas futuras}

Como proyección de los estudios internodales, deberemos adentrarnos en el futuro en nuevas dimensiones, como es el rol preponderante que revelan los senderos en la construcción ontológica de las sociedades andinas, tal como se constata con nitidez en la etnografía aymara (p.e., Martínez 1976; Abercrombie 1998; Arnold y Yapita 1998). Se deberá reconectar de algún modo nuestros registros arqueológicos internodales con la importancia ontológica y estructural que poseen los senderos en el mundo andino histórico y contemporáneo. Después de todo, dicha construcción debería encontrar sus antecedentes primigenios en la ontología andina prehispánica.
Cuando G. Martínez (1976: 272) destacaba en Isluga "que antes de emprender un viaje es costumbre ch'allar el camino con alcohol puro, coca y la fórmula: Thaki mallku, thaki talla suma iripitanta. Como decir, más o menos: señor camino, señora camino, me vas a llevar bien", él reconocía que los senderos son concebidos como una verdadera entidad viva con la que el ser humano está tratando directamente, no es sólo una imagen metafórica, ya que en la lógica andina ese imaginario mental es dependiente de la reciprocidad ritual y material que se establezca con dicha entidad, determinando finalmente el éxito o fracaso del viaje.

"Todo debe tener su sendero. [...] Por eso, [...] deben gritar los nombres de las sendas de los animales en sus canciones y libaciones. Si no se incorporan las sendas en sus canciones, luego los animales no tendrían por donde andar" (Arnold y Yapita 1998: 193). Que todo deba tener su propio sendero se vincula al mismo tiempo con construcciones de senderos tanto imaginarios metafóricos andinos (p.e., el sendero blanco que conecta con la Vía Láctea), como con los trayectos concretos en los senderos del espacio terrenal. Entre ambos mundos, el de los senderos celestiales y el de los terrenales, las comunidades andinas funden lo imaginario y lo real, inscribiéndose en lo tangible y en la repetición ritual en el espacio.

Como los "senderos de la memoria" que analiza agudamente Abercrombie (1998), en el que thaki (sendero en aymara) es la raíz semántica de un complejo campo lingüístico que conecta con una multiplicidad de mundos como la memoria, las secuencias libatorias, las narrativas orales del pasado, el ciclo de canciones, las "carreras" de fiestas, cargos religiosos y de cargos políticos. La memoria es concebida en rigor como senderos, no solamente como una metáfora vial al estilo occidental ("los caminos de la vida" o "el camino de Dios"), sino como una constitución práctica, con senderos reales que conectan con lugares concretos y con deidades tan reales como su propia realidad recreada. Es en la imagen gráfica de los senderos donde se fragua la historia, el pasado y las relaciones de equilibrio con las deidades y con los antepasados. En el otro extremo ontológico de Occidente, en el que la historia se encierra en la palabra escrita en los libros y se funda en el destino (ciudad/marka), en el mundo andino la historia, el pasado y el devenir se despliegan en el itinerario, en el viaje y como recorrido (internodo/pampa). Tal como el Thaki primordial 


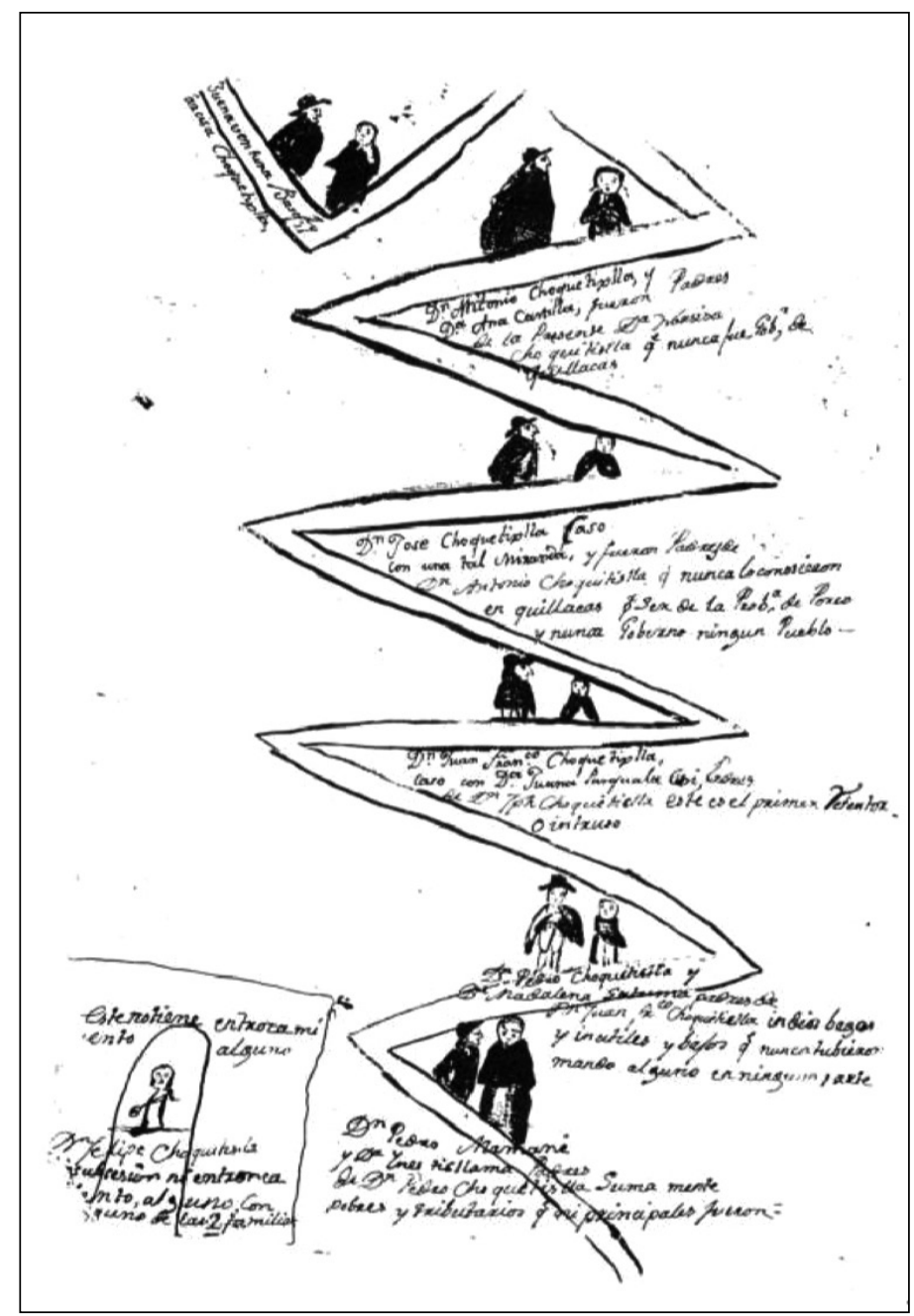

Figura 1. El árbol genealógico se representa como "Camino genealógico" a principios del siglo XIX (1804). "Camino familiar" de Choqueticlla, con el mendigo Choqueticlla aislado, afuera, doblemente encerrado y "sin camino" (Abercrombie 1998: 229).

("el recorrido del sol"), la historia es una narración de viaje que se encuentra inscrita en el espacio.

La contraparte del "árbol genealógico" occidental se representaba a principios del siglo XIX como "camino genealógico" (Figura 1), a partir del cual se vincula el pasado y el presente como una continuidad espacio-temporal, funcionando la imagen del sendero como una forma de cronotopo. Amt'añ thaki, senderos de la memoria, por ejemplo, es usado para referirse a las secuencias de ch'allas que evocan lugares, en la forma de un viaje mental. "Son filas de actos seriados en movimiento que comienzan, subjetivamente, en un lugar y en un tiempo y acaban en otro: se los puede concebir a todos como tipos de itinerarios o derroteros de viaje" (Abercrombie 1998:320), por lo que los seres humanos recuerdan y se dirigen a los dioses. En el análisis de Abercrombie (1998), thaki puede ser considerado tanto una técnica de producción de comunidad política como una forma aymara de poética que se funde con la historia.

Así, en el espacio de la memoria nos encontramos directamente ante su manifestación, en la que los senderos guardan parte de esa memoria que nos conecta con la 
historia andina en su propio entramado mnemotécnico. De los "senderos de la memoria" entonces habrá que producir el giro arqueológico y apostar por desentrañar la "memoria de los senderos". Las múltiples inscripciones que se encuentran a la vera de los senderos prehispánicos, ya sean representaciones de geoglifos, grabados 0 pinturas, o contextos de ofrendas rituales, son todas expresiones que marcan y remarcan esa memoria inscrita.

¿Por qué los espacios de circulación se hallan tan fuertemente ritualizados? Como lo ha planteado últimamente Berenguer (2016; véase también Gallardo et al. 2017), en los Andes muchos de los espacios geográficos que llamamos internodales son conocidos como "pampas". En general, estas geo-formas son definidas en los diccionarios como extensiones llanas, pero el concepto andino admite también la idea de pampas onduladas. Siempre según esta propuesta, es sabido por los trabajos de Cereceda (1978) que las tejedoras aymaras usan el término "pampa" al describir las llicllas e inkuñas. La "pampa" en estos paños ceremoniales es esa parte sin nada, vacía, continua y tejida con lana natural, situada entre franjas teñidas en distintos colores que hablan, más bien, de contenidos y de discontinuidades. Mientras para las tejedoras las franjas representan lo cultural y lo estable, la "pampa" representa lo no cultural, lo salvaje. Así, podría pensarse que las pampas o internodos fueron percibidos por los viajeros como zonas silvestres, peligrosas, a veces impredecibles y sobre todo liminales, las que no se podían cruzar sin efectuar los debidos protocolos rituales. Esto explicaría en parte los geoglifos, sepulcros, muros y cajas, columnas y acumulaciones de piedras que puntúan las extensas rutas entre los nodos poblacionales. Sin duda, el giro ontológico y las aproximaciones cognitivas andinas, con sus homologías textiles y geomórficas, constituyen aproximaciones que abren nuevas avenidas en las, a estas alturas, multifacéticas dimensiones de los estudios internodales.

Los senderos de la ontología andina nos exigen en definitiva preponderar una mirada integral y de continuidad espacio-temporal, que tenga como efecto permanente el poder reconectar los nodos e internodos, la marca y la pampa, el destino y el viaje.

\section{* Referencias citadas}

ABERCROMBIE, T.A. 1998. Pathways of memory and Power. Ethnography and History Among an Andean People. The University of Wisconsin Press, Wisconsin.

ARNOLD, D. y J. YAPITA. 1998. Río de vellón, Río de canto. Hisbol, La Paz, Bolivia.

ARONSON, S. 2008. Aridscapes. Proyectar en tierras ásperas y frágiles / designing in harsh and fragile lands. Land \& Scape Series, Editorial Gustavo Gili, Barcelona.

BERENGUER, J. 1994. Asentamientos, caravaneros y tráfico de larga distancia en el norte de Chile: El caso de Santa Bárbara. En De costa a selva: Intercambio y producción en los Andes Centro-Sur, Ma. E. Albeck (Ed.), pp. 17-50. Instituto Interdisciplinario Tilcara / Universidad de Buenos Aires, Buenos Aires.

BERENGUER, J. 1995. Impacto del caravaneo prehispánico tardío en Santa Bárbara. En Actas del XIII Congreso Nacional de Arqueología Chilena (Hombre y Desierto 9), pp. 185-202. Sociedad Chilena de Arqueología / Universidad de Antofagasta, Antofagasta.

BERENGUER, J. 2002. Tráfico de caravanas, interacción interregionaly cambio cultural en la prehistoria tardía del desierto de Atacama. Ph.D. dissertation, Department of Anthropology, University of Illinois at Urbana-Champaign. University Microfilms, Ann Arbor.

BERENGUER, J. 2004. Caravanas, interacción y cambio en el desierto de Atacama. Ediciones Sirawi / LOM Editores, Santiago.

BERENGUER, J. 2016. Pampas geográficas y pampas tejidas: homologías textiles para el binomio nodal - internodal. Paper presentado al $4^{\circ}$ Taller de Sistemas de Representación Andinos, Problemas, metodologías y materialidades, TASIRA IV, Museo Chileno de Arte Precolombino, Santiago.

BERENGUER, J., I. CÁCERES, C. SANHUEZA y P. HERNÁNDEZ. 2005. El Qhapaqñan en el Alto Loa, Región de Antofagasta: Un estudio micro y macromorfológico. Estudios Atacameños 29: 7-39.

BERENGUER, J., C. SANHUEZA e I. CÁCERES. 2011. Diagonales incaicas, interacción interregional y dominación en el altiplano de Tarapacá, norte de Chile. En En ruta, arqueología, historia y etnografía del tráfico sur andino, L. Núñez y A. Nielsen (Eds.), pp. 247-283, Encuentro Grupo Editor, Córdoba. 
BERENGUER, J. y G. PIMENTEL. 2010. Introducción. Simposio Arqueología de los "espacios vacíos": una aproximación internodal a las relaciones intersocietales. En Actas del XVII Congreso Nacional de Arqueología Chilena, Valdivia 2006, pp. 1305-1308. Sociedad Chilena de Arqueología / Universidad Austral de Chile, Valdivia.

BITTMAN, B. 1985. Reflections on geoglyphs from Northern Chile. Rickmansworth, England: H.B.C. Publications, Latin American Studies 1.

BLANCO, J. F., M. DE LA MAZA y C. REES. 2011. Cazadores recolectores costeros y el aprovisionamiento de recursos líticos. Perspectivas interpretativas de los eventos de talla en el desierto absoluto. Werkén vol. 13, núm. 2: 45-68.

BRIONES, L., L. NÚÑEZ y V. G. STANDEN. 2005. Geoglifos y tráfico prehispánico de caravanas de llamas en el Desierto de Atacama (norte de Chile). Chungara. Revista de Antropología Chilena 37 (2): 195-223.

BROWMAN, D. L. 1980. Tiwanaku expansion and Altiplano economic patterns. Estudios Arqueológicos 5: 107-120.

CASES, B., C. REES, G. PIMENTEL, R. LABARCA y D. LEIVA. 2008. Sugerencia desde un contexto funerario en un "espacio vacío" del desierto de Atacama. Boletín del Museo Chileno de Arte Precolombino 13(1): 51-70.

CERECEDA, V. 1978. Les talegas d'Isluga. Sémiologie des tissues andins. Annales, E. S. C. 33 (5-6): 1017-1035, Paris.

GALLARDO, F., G. CABELLO y G. PIMENTEL. 2017. Signs in the desert: geoglyphs as cultural system and ideology (Northern Chile). Archaeologies of Rock Art: South American Perspectives, A. Troncoso, F. Armstrong y G. Nash (Eds.). En Prensa.

LIGHTFOOT, K. G. y A. MARTÍNEZ. 1995. Frontiers and boundaries in archaeological perspective. Annual Reviews in Anthropo$\log 2$ 24: 471-492.

LYNCH, T. F. 1989. Regional interaction, transhumance, and verticality: Archaeological use of zonal complementarity in Peru and Northern Chile. En Michigan Discussions in Anthropology 8: 1-11, Ann Arbor.

MARTÍNEZ, G. 1976. El sistema de los Uywiris en Isluga. En Homenaje al Dr. R. P. Gustavo Le Paige, L. Núñez (Ed.), pp. 255-327. Universidad del Norte, Antofagasta.

NIELSEN, A. 1997. El tráfico caravanero visto desde La Jara. Estudios Atacameños 14:339-371.
NIELSEN, A. 2000. Andean Caravans: An Ethnoarchaeology. Ph.D. dissertation, Department of Anthropology, University of Arizona. University Microfilms, Ann Arbor.

NIELSEN, A. 2006. Estudios internodales e interacción interregional en los Andes Circumpuneños: Teoría, método y ejemplos de aplicación. En Esferas de interacción prehistóricas y fronteras nacionales modernas en los Andes Sur Centrales, H. Lechtman (Ed.), pp. 29-62. Instituto de Estudios Peruanos e Institute of Andean Research.

NIELSEN, A., J. BERENGUER y G. PIMENTEL. 2017. Ms. Internodal Archaeology and Mobility in the Andes of Capricorn During the Late Intermediate Period (1000-1400 C.E.).

NÚÑEZ, L. 1985. Petroglifos y tráfico de caravanas en el desierto chileno. En Estudios en arte rupestre, C. Aldunate, J. Berenguer y V. Castro (Eds.), pp. 243-264. Museo Chileno de Arte Precolombino, Santiago.

NÚÑEZ, L. y T.D. DILLEHAY. 1979. Movilidad giratoria, armonía social y desarrollo en los Andes Meridionales: Patrones de tráfico e interacción económica (Ensayo). Universidad del Norte, Antofagasta.

NÚÑEZ, L.; V. ZLATAR y P. NÚÑEZ. 1975. Relaciones prehistóricas trasandinas entre el N.O. argentino y norte de Chile (Período Cerámico). Serie Documentos de Trabajo 6: 1-25, Antofagasta.

PIMENTEL, G. 2009. Las huacas del tráfico. Arquitectura ceremonial en rutas prehispánicas del desierto de Atacama. Boletín del Museo Chileno de Arte Precolombino 14(2): 9-38.

PIMENTEL, G. 2011. Geoglifos e imaginarios sociales en el Desierto de Atacama (Región de Antofagasta, Chile). Temporalidad, interacción y dinamismo cultural. La búsqueda del Hombre. Homenaje al Profesor Lautaro Núñez Atencio, A. Hubert, J. A. González y M. Pereira (Eds.), pp. 163-200. Ediciones Universitarias Universidad Católica del Norte, Antofagasta.

PIMENTEL, G. 2013. Redes Viales Prehispánicas en el Desierto de Atacama. Viajeros, Movilidad e Intercambio. Tesis para optar al grado de Doctor en Antropología. Universidad Católica del Norte y Universidad de Tarapacá, San Pedro de Atacama.

PIMENTEL G., C. REES, P. DE SOUZA y L. ARANCIBIA. 2011. Viajeros costeros y caravaneros. Dos estrategias de movilidad en el Período Formativo del desierto de Atacama, Chile. En En ruta, arqueología, historia y etnografía del tráfico sur andino, L. Núñez y A. Nielsen (Eds.). Encuentro Grupo Editor, Córdoba.

PIMENTEL, G., M. UGARTE F., F. GALLARDO, J. BLANCO y C. MONTERO. 2017. Chug-Chug en el contexto de la movilidad Internodal prehispánica en el desierto de Atacama, 
Chile. Chungara AOP. http: //dx.doi.org/10.4067/So71773562017005000102

TAPIA LADINO, M. y C. OVANDO SANTANA. 2013. Los Andes tarapaqueños, nuevas espacialidades y movilidad fronteriza: ¿Barrera geográfica o espacio para la integración? En Fronteras en movimiento e imaginarios geográficos: La cordillera de los Andes como espacialidad sociocultural, A. Núñez, R. Sánchez y F. Arenas (Eds.), pp. 243-274. RIL Editores, Santiago.

TARRAGÓ, M. 1984. La historia de los pueblos circumpuneños en relación con el altiplano y los Andes Meridionales. Estudios Atacameños 7: 116-132.

TARRAGÓ, M. 1989. Contribución al conocimiento arqueológico de las poblaciones de los oasis de Atacama en relación con otros pueblos puneños. Tesis de Doctorado, Facultad de Humanidades y Artes, Universidad Nacional de Rosario, Rosario.

TARRAGÓ, M. 1994. Intercambio entre Atacama y el borde de puna. En Taller de costa a selva, Ma. E. Albeck (Ed.), pp. 199-213. Instituto Interdisciplinario Tilcara / Universidad de Buenos Aires, San Salvador de Jujuy.

TARRIUS, A. 2000. Leer, describir, interpretar las circulaciones migratorias: Conveniencia de la noción de territorio circulatorio. Los nuevos hábitos de la identidad. Relaciones. Estudios de historia y sociedad, vol. XXI, núm. 83:39-66.

TORRES-ROUFF, C., G. PIMENTEL y M. UGARTE. 2012. ¿Quiénes viajaban? Investigando la muerte de viajeros post arcaicos en el Desierto de Atacama (ca. 800 AC-1536 DC). Estudios Atacameños. Arqueología y Antropología Surandinas 43: 167-186.

TROMBOLD, C.D. 1991. An introduction to the study of ancient New World road networks. En Ancient road networks and settlement hierarchies in the New World, C.D. Trombold (Ed.), pp. 1-9. Cambridge University Press.
SANHUEZA, C. 2012. Las 'sayhuas' del Inca. Territorio, frontera, geografía sagrada y 'cartografía' oral en el desierto de Atacama. Tesis para optar el grado de Doctora en Historia con Mención en Estudios Andinos, Pontificia Universidad Católica de Chile, Santiago.

SMITH, M. y P. HESSE. 2005. Capricorn's deserts. En $23^{\circ} \mathrm{S}$. Archaeology and Environmental History of the Southern Deserts, M. Smith y P. Hesse (Eds.), pp. 1-12. National Museum of Australia Press, Canberra.

SMITH, M., P. VETH, P. HISCOCK y L.A. WALLIS. 2005. Global Deserts in Perspective. En Desert Peoples. Archaeological Perspectives. Blackwell Publishing Ltd., London.

SOJA, E.W. 1989. Postmodern Geographies: The Reassertion of Space in Critical Social Theory. Verso, London.

SVAMPA, M. 2008. La disputa por el desarrollo: territorio, movimientos de carácter socio-ambiental y discursos dominantes. En Cambio de época. Movimientos sociales y poder político, M. Svampa. Siglo XXI, Buenos. Aires.

UPHAM, S. 1992. Interaction and isolation: The empty spaces in panregional political and economic systems. En Resources, power, and interregional interaction, E.M. Schortman y P.A. Urban (Eds.), pp. 139-152. Plenum Press, New York.

VETH, P. 2005. Conclusion: Major Themes and Future Research Directions. En Desert Peoples. Archaeological Perspectives, P. Veth, M. Smith y P. Hiscock (Eds.), pp. 293-300. Blackwell Publishing Ltd., London. 